\title{
Seroprevalencia contra Bordetella pertussis en embarazadas vacunadas y no vacunadas y neonatos en un hospital universitario de la provincia de Buenos Aires
}

Seroprevalence of Bordetella pertussis among vaccinated
and unvaccinated pregnant women and newborn infants in a
university hospital of Buenos Aires

Dr. Juan J. Boscha, Dra. Hilaria Fernández ${ }^{a}$, Dr. Fernando P. Polak ${ }^{b}$

Dr. Gabriel Musante ${ }^{a}$, Dra. Romina Libster y Dr. Manuel Rocca Rivarola ${ }^{a}$

\section{RESUMEN}

Introducción. La tos convulsa es una enfermedad altamente contagiosa causada por Bordetella pertussis. Tiene una alta tasa de morbilidad y mortalidad, especialmente, en los lactantes menores de seis meses de edad. En la Argentina, la incidencia y la mortalidad se han encontrado en aumento en las últimas 3 décadas.

Objetivo. Determinar anticuerpos contra Bordetella pertussis en las mujeres embarazadas en el tercer trimestre de la gestación y en el recién nacido, medidos en la sangre del cordón.

Métodos. Se diseñó un estudio observacional, transversal. El estudio se inició en 2011 cuando la vacunación contra pertussis en la embarazada no estaba incluida en el Calendario Nacional de Vacunación y era opcional. Los anticuerpos se midieron en las madres en el tercer trimestre del embarazo y en la sangre del cordón umbilical al nacer. Las determinaciones de anticuerpos se realizaron con el kit de ELISA humano para IgG toxina pertussis $\mathrm{ABCAM}^{\circledR}$. Se utilizó la prueba de $\mathrm{chi}^{2}$ para comparar la prevalencia.

Resultados. Seincluyóa 111 madres y a susbebés, 35 hijos de madres no vacunadas (antes de la implementación de la vacuna en embarazadas) y 76 hijos de madres vacunadas. Los bebés de madres vacunadas presentaron anticuerpos IgG positivos en el $92 \%$ (70/76), mientras que los bebés de madres no vacunadas fueron negativos para anticuerpos IgG en el $100 \%(35 / 35)$ con una $\mathrm{p}<0,001$.

Conclusión. En la población de vacunadas del estudio, se observó que sus hijos presentaron anticuerpos IgG positivos en el $92 \%$. Este estudio apoya la necesidad de la inmunización materna contra Bordetella pertussis para proteger al recién nacido.

Palabras clave: tos convulsa, toxina del pertussis, anticuerpos, inmunización materna.

http: / / dx.doi.org/10.5546/ aap.2017.311

Texto completo en inglés:

http:/ / dx.doi.org/10.5546/ aap.2017.eng.311

en Medicina de la
Fundación Florencio

Fiorini, 2013.

Conflicto de intereses:

Ninguno que declarar.

Recibido: 15-10-2016

Aceptado: 4-1-2017
Cómo citar: Bosch JJ, Fernández H, Polak FP, et al. Seroprevalencia contra Bordetella pertussis en embarazadas vacunadas y no vacunadas y neonatos en un hospital universitario de la provincia de Buenos Aires. Arch Argent Pediatr 2017;115(4):311-315.

\section{INTRODUCCIÓN}

La tos convulsa o coqueluche es una enfermedad altamente contagiosa causada por Bordetella pertussis. Presenta una elevada tasa de morbimortalidad, en especial, en individuos parcialmente inmunizados, y los neonatos son el grupo de mayor riesgo. ${ }^{1}$

En la Argentina, la incidencia disminuyó a partir de la introducción de la vacuna triple bacteriana en la década del sesenta (triple bacteriana: tétanos, difteria y pertussis) hasta 2003 (639 casos; 1,8/100000 habitantes), año en el que comenzó la reemergencia hasta llegar a 2005, cuando los casos ascendieron a 2060 con una tasa de notificación de 5,7/ 100000 habitantes. ${ }^{2}$

El aumento de Bordetella pertussis en adolescentes y adultos jóvenes los convierte en reservorio y potenciales transmisores de coqueluche a los grupos de riesgo menos protegidos, como los neonatos, quienes presentan una mayor tasa de morbimortalidad.

Desde el año 2009, el Calendario Nacional de Vacunación contempla la vacuna triple bacteriana contra difteria, tétanos y pertussis (Tdap) a los 11 años $\mathrm{y}$, posteriormente, se incluyó a las embarazadas a partir de la semana 20 de embarazo, primero como campaña a partir de febrero de 2012 y luego ya establecida como obligatoria en el Calendario Nacional de Vacunación en enero de 2014. ${ }^{3}$

En la actualidad, la indicación aclara que debe recibirse en cada 
embarazo y se incluye también a puérperas que no se hayan vacunado durante el embarazo, al personal de salud que presta cuidado a niños menores de un año y a convivientes con prematuros menores de 1500 gramos. ${ }^{4}$

Recientemente, se publicaron los datos de la Dirección Nacional de Control de Enfermedades Inmunoprevenibles (DiNaCEI) del Ministerio de Salud de la Nación Argentina: se reportó una tasa de cobertura materna con vacuna contra Tdap del 50,9\% en el primer año de campaña (2012) y se alcanzó una tasa de cobertura del $67,2 \%$ en 2013. Se evidenció una caída de la incidencia de pertussis del 60\% entre 2011 y 2013, que pasó de 2821 casos reportados en 2011 a 1117 en 2013. ${ }^{5}$

El $90 \%$ de infectados por Bordetella pertusiss son menores de 1 año (el 75\% corresponde a menores de 6 meses); 6 el 50\% necesitan internación y la tasa de mortalidad es del 6\% al 9\%. ${ }^{7}$ En la República Argentina, al igual que en Holanda y en Estados Unidos, la incidencia y la mortalidad han estado en aumento en las últimas 3 décadas. La falla para inducir inmunidad duradera con las vacunas actuales y la divergencia antigénica entre las cepas locales y las vacunas agravarían el efecto de la menguante inmunidad. ${ }^{8}$

Nuestra hipótesis era que la presencia de anticuerpos maternos se relacionaba con la presencia de anticuerpos en el recién nacido. El objetivo del trabajo fue determinar la presencia de anticuerpos contra Bordetella pertussis de la madre en el tercer trimestre del embarazo y del neonato en la sangre del cordón, en relación con la vacunación materna.

\section{POBLACIÓN Y MÉTODOS}

Se llevó a cabo un estudio observacional, de corte transversal desde agosto de 2011 a mayo de 2014 en el Hospital Universitario Austral.

Cuando comenzó el estudio, la vacunación en la embarazada contra pertussis no era obligatoria. Luego, en febrero de 2012, el Ministerio de Salud de la Nación inició la campaña de vacunación en la embarazada y, finalmente, se incluyó en el Calendario Nacional de Vacunación en enero de 2014.

El Hospital atiende a una gran población de la zona norte del Gran Buenos Aires y es la segunda maternidad más importante del partido de Pilar. En el Hospital, nacen alrededor de 2000 niños por año y un $4 \%$ de las pacientes que se siguen allí luego tienen el parto en otras instituciones.

Se invitó a participar del estudio a todas las mujeres embarazadas con seguimiento en el
Hospital mediante un consentimiento informado escrito evaluado y aprobado por el Comité de Evaluación Institucional del Hospital Universitario Austral y por el Comité de Ética Central del Ministerio de Salud de la Provincia de Buenos Aires. Número de expediente 2919/269/11.

\section{Criterios de inclusión}

Se incluyeron las embarazadas mayores de 18 años, con consentimiento informado escrito $\mathrm{y}$ a quienes se les extrajo sangre en la rutina del tercer trimestre del embarazo en el Hospital y cuyo parto se realizó en el Hospital.

Se incluyeron los recién nacidos vigorosos a los cuales se les tomó muestra de sangre del cordón suficiente para medir la presencia de anticuerpos contra la toxina pertussis.

\section{Criterios de exclusión}

Se excluyeron pacientes con puntaje de Apgar no vigoroso o que su situación al nacer no permitía la recolección de la muestra, embarazos gemelares, madres incapaces de dar consentimiento por sí mismas o menores de 18 años al momento de la firma del consentimiento informado y a quienes no se les extrajo sangre en la rutina del tercer trimestre.

Se eliminaron del análisis aquellas madres que no continuaron su seguimiento en el Hospital o que tuvieron el parto en otra institución.

\section{Procedimientos del estudio}

Se tomó y almacenó una alícuota de $500 \mu \mathrm{lt}$ de suero de la muestra de sangre que se realizó de rutina en la embarazada en el tercer trimestre del embarazo. Se identificaron las muestras en forma anónima con código de identificación alfanumérico.

En el caso del recién nacido, se tomó una alícuota de $500 \mu$ lt de la muestra de sangre del cordón que se extraía de rutina para determinaciones de grupo y factor, y se obtuvo luego de dicha determinación. Esta muestra fue rotulada a fin de parearla con la muestra materna correspondiente.

Las muestras fueron conservadas y refrigeradas a $-70^{\circ} \mathrm{C}$ en el laboratorio del Hospital Austral.

Las mediciones de anticuerpos se realizaron todas en forma simultánea una vez finalizado el estudio. Se utilizó el kit de ELISA humano para IgG toxina pertussis $\mathrm{ABCAM}^{\circledR}$.

Se evaluaron las variables maternas edad, nivel educacional, antecedentes de enfermedad 
materna, síndrome antifosfolipídico, tabaquismo, estado de vacunación materno. También, antecedentes del embarazo, como hipertensión arterial, diabetes gestacional, hipotiroidismo, uso de corticoides en el embarazo, tabaquismo o alcohol durante el embarazo, número de controles en el embarazo, número de gesta, tipo de finalización del embarazo (parto o cesárea), infecciones en el embarazo u otras patologías que afectaran la unidad feto-placentaria.

Las variables evaluadas en el recién nacido fueron sexo, edad gestacional, peso y puntaje de Apgar al primer minuto y a los 5 minutos.

Se realizó la prueba de $\mathrm{chi}^{2}$ para comparar la prevalencia, tomando como significativa una $\mathrm{p}<0,05$. El análisis estadístico fue realizado con el programa Epi Info $7^{\circledR}$.

\section{RESULTADOS}

Durante la realización del protocolo, nacieron en el Hospital 3398 niños; 2883 cumplieron criterios de elegibilidad para el estudio. De las 215 madres que firmaron el consentimiento, se obtuvo la muestra del tercer trimestre de 181. De estas, 59 no tuvieron el parto en el Hospital y, en otras 11, no se logró obtener la muestra de sangre del cordón por diferentes circunstancias (6 niños por puntaje de Apgar no vigoroso y 5 por muestra insuficiente). Finalmente, se incluyeron 111 madres y sus bebés; 35 hijos de madres no vacunadas y 76 hijos de madres vacunadas en el segundo trimestre del embarazo.

El promedio de edad de las madres enroladas fue de 30 años y no hubo diferencias entre los grupos. Una sola madre tenía entre 18 y 20 años; 51 madres tenían entre 20 y 30 años; 43 madres tenían entre 31 y 35 años; y 16 madres eran mayores de 35 años. El $80 \%$ de las madres presentaba secundario completo; $10 \%$ se encontraba cursando el secundario y el otro $10 \%$ tenía primario completo. El 90\% realizó más de 5 controles durante el embarazo, y el otro $10 \%$ realizó más de 3 controles.

La edad gestacional promedio de los bebés al nacer fue de 39 semanas; 3 nacieron de 37 semanas; 19, de 38 semanas; 68, de 39 semanas; 16 , de 40 semanas; y 5 , de 41 semanas. El peso promedio fue de $3,475 \mathrm{~kg} ; 7$ pesaron entre $2 \mathrm{y}$ $2,5 \mathrm{~kg} ; 58$, entre 2,5 y 3,5 kg; y 46, > 3,5 kg (véase la Tabla 1). El puntaje de Apgar al primer minuto fue 7 en dos pacientes con circular de cordón y $>8$ a los 5 minutos en todos los pacientes.

Los bebés de madres vacunadas presentaron anticuerpos IgG positivos en el 92\% (70/76), mientras que los bebés de madres no vacunadas fueron negativos para anticuerpos IgG en el $100 \%(35 / 35)$ con una $p<0,001$. Dentro de las madres vacunadas, hubo un $8 \%$ de bebés que no presentaron anticuerpos contra pertussis. Estas 6 madres no tenían antecedentes de importancia.

No se encontraron diferencias entre ninguna de las variables evaluadas y la presencia o no de anticuerpos, a excepción del antecedente de vacunación.

\section{DISCUSIÓN}

Se realizaron múltiples estudios para evaluar la presencia de anticuerpos protectores contra Bordetella pertussis en forma pareada en madres y en la sangre del cordón., ${ }^{9,10}$

En nuestro estudio, las madres no vacunadas tuvieron bebés con anticuerpos negativos en la sangre del cordón y la gran mayoría de las madres vacunadas tuvieron bebés con anticuerpos positivos en la sangre de cordón.

En el estudio de Nooitgedagt y colaboradores, se vio que las madres con bajos títulos de anticuerpos transferían menor concentración de anticuerpos, lo que dejaba al recién nacido con riesgo aumentado para adquirir la enfermedad durante los primeros meses de vida. ${ }^{11}$

TABLA 1. Características demográficas y principales variables evaluadas de la población estudiada

\begin{tabular}{lcc}
\hline \multicolumn{3}{c}{ Madres (n: 111) } \\
\hline & Vacuna, sí & Vacuna, no \\
\hline & & \\
$\mathrm{n} / \%$ & $76 / 68,5 \%$ & $35 / 31,5 \%$ \\
Edad $\bar{x}$ & 29,9 & 30 \\
$\%$ de cesáreas & $38 \%$ & $39 \%$ \\
$\%$ de TBQ & $6,30 \%$ & $5,80 \%$ \\
$\%$ de HTA G & $5,00 \%$ & $5,10 \%$ \\
$\%$ de hipotiroidismo & $9,60 \%$ & $9,00 \%$ \\
DBT G & $11,53 \%$ & $10,90 \%$ \\
SAF & $5,70 \%$ & $5,90 \%$ \\
ITU & $5,10 \%$ & $5,10 \%$ \\
Colestasis & $1,70 \%$ & $0,00 \%$ \\
\hline & Bebés (n: 111) \\
\hline & Vacuna, sí & Vacuna, no \\
\hline EG $\bar{x}$ & 39,36 & 39 \\
Peso $\bar{x}$ & 3420 & 3530 \\
$\%$ masculino & $50 \%$ & $53 \%$ \\
\hline
\end{tabular}

TBQ: tabaquismo; HTA G: hipertensión arterial gestacional; DBT G: diabetes gestacional; SAF: síndrome antifosfolipídico; ITU: infección urinaria; EG: edad gestacional. 
En el trabajo argentino de la Dra. Fallo de seroprevalencia de coqueluche en adultos jóvenes, mujeres en puerperio inmediato y sangre del cordón umbilical, se midieron anticuerpos totales anti-Bordetella contra célula entera, y se encontró que tanto las madres como los cordones umbilicales tenían títulos bajos de anticuerpos, lo que evidenció los menores títulos de anticuerpos en las mujeres de 25 a 39 años. ${ }^{12}$

La concentración de anticuerpos transplacentarios contra pertussis declina en el niño con una vida media de 6 semanas y, para la edad de 6 meses, no hay anticuerpos detectables contra Bordetella pertussis. Aun con efectivo pasaje transplacentario de anticuerpos, la inmunidad pasiva del neonato es insuficiente. . $^{13-15}$

En el Calendario Nacional de Vacunación, está indicada la vacuna celular contra pertussis a los 2, 4, 6 meses, luego refuerzos a los 18 meses, 6 y 11 años, y luego cada 10 años. Los individuos que reciben solo vacuna acelular tienen menor inmunidad, ya que sus niveles de anticuerpos declinan hacia los 4 años de recibida la vacuna. ${ }^{16}$ Es por eso por lo que, en la embarazada, se decidió incorporar, desde este año, el uso de vacuna triple acelular en cada embarazo.

En nuestro trabajo, la principal variable asociada a la presencia de anticuerpos en la sangre del cordón del recién nacido fue la vacunación de la embarazada. Dentro de los factores relacionados con el pasaje transplacentario de anticuerpos, los más importantes serían la edad gestacional, la presencia de infecciones de la madre y la concentración materna de anticuerpos. ${ }^{17}$

En el estudio de Heininger, se vio que los nacidos pretérmino tenían niveles más bajos de anticuerpos contra pertussis y que el radio de transferencia transplacentaria era mayor en los niños nacidos a término. ${ }^{15}$ Healy y col. observaron que la concentración de anticuerpos contra la toxina pertussis era menor en madres adolescentes de origen hispano. ${ }^{18}$ Si bien este estudio carece de un grupo control de población no hispana, coincide con el trabajo de Plans y col., en el que se evidenció que la presencia de anticuerpos disminuía con la edad. ${ }^{19}$ A su vez, los hijos de madres adolescentes tuvieron mayor riesgo de contraer tos convulsa. ${ }^{20}$

En nuestro trabajo, no se incluyeron recién nacidos pretérmino y la edad materna no tuvo relación con la presencia o no de anticuerpos, aunque no se incluyeron madres menores de 18 años y una sola madre fue menor de 20 años.
En la evaluación del programa británico de inmunización materna contra pertussis, se evidenció, aproximadamente, $90 \%$ de protección contra la enfermedad a 3 años de seguimiento, sostenido a pesar de haber cambiado de una vacuna acelular de 3 componentes, como la utilizada en nuestro trabajo, a una vacuna de 5 componentes. ${ }^{21,22}$

Este trabajo se realizó aprovechando las intervenciones habituales de las embarazadas en seguimiento en el Hospital y tomando la muestra de sangre del cordón luego de la determinación de grupo y factor de rutina. Esta característica representa ciertas limitaciones que se deben mencionar: si bien la vacunación en la embarazada se realizó en el segundo trimestre del embarazo, no sabemos la fecha exacta de vacunación. Esto podría ser importante al evaluar el $8 \%$ de madres vacunadas con bebés con anticuerpos negativos, ya que puede no haber transcurrido tiempo suficiente para que la madre desarrollara anticuerpos por la vacunación y que estos no se encontraran elevados en el mejor momento de transferencia placentaria de anticuerpos.

En febrero de 2016, la actualización del Comité de Vacunación e Inmunizaciones del Reino Unido (Joint Committee on Vaccination and Immunisation; JCVI, por sus siglas en inglés) recomendó que la vacunación en la embarazada debía ser, idealmente, antes de la semana 28 para lograr mayor pasaje transplacentario de anticuerpos al feto. ${ }^{23}$ Hay estudios que recomiendan la vacunación temprana en el segundo trimestre, con mejores resultados entre las semanas 13 y $25 .^{24}$

El kit de anticuerpos utilizado es cualitativo y da información acerca de la presencia o no de anticuerpos y no puede realizar concentraciones geométricas medias para medir la cantidad de pasaje de anticuerpos.

\section{CONCLUSIÓN}

En la población de vacunadas del estudio, se observó que sus hijos presentaron anticuerpos IgG positivos en el 92\%. Este estudio apoya la necesidad de la inmunización materna contra Bordetella pertussis para proteger al recién nacido.

\section{Agradecimientos}

Al Departamento de Desarrollo Académico del Hospital Universitario Austral por la ayuda brindada en el área estadística y de corrección del trabajo, a las bioquímicas Silvina Coviello y Sandy Yoder por su ayuda en la concepción del estudio. 


\section{REFERENCIAS}

1. Centers for Disease Control and Prevention (CDC). Pertussis--United States, 1997-2000. MMWR Morb Mortal Wkly Rep 2002;51(4):73-6.

2. Hozbor D, Mooi F, Flores D, Weltman G, et al. Pertussis epidemiology in Argentina: trends over 2004-2007. J Infect 2009;59(4):225-31.

3. Vizzotti C, Neyro S, Katz N, Juárez MV, et al. Maternal immunizationin Argentina: Astorylinefrom the prospective of a middle income country. Vaccine 2015;33(47):6413-9.

4. Dirección de Control de Enfermedades Inmunoprevenibles. Tos convulsa. Buenos Aires: Ministerio de Salud de la Nación; 2015. [Acceso: 6 de enero de 2017]. Disponible en: http: / / www.msal.gob.ar/dicei/index.php/ciudadanos / vacunas-del-calendario/353-tos-convulsa.

5. Vizzotti C, Juarez MV, Bergel E, Romanin V, et al. Impact of a maternal immunization program against pertussis in a developing country. Vaccine 2016;34(50):6223-8.

6. Gentile A. Infección por Bordetella pertussis. Arch Argent Pediatr 2010;108(1):78-81.

7. Broder KR, Cortese MM, Iskander JK, Kretsinger $\mathrm{K}$, et al. Preventing tetanus, diphtheria, and pertussis among adolescents: use of tetanus toxoid, reduced diphtheria toxoid and acellular pertussis vaccines recommendations of the Advisory Committee on Immunization Practices (ACIP). MMWR Recomm Rep 2006;55(RR-3):1-34.

8. Mooi FR, de Greeff SC. The case for maternal vaccination against pertussis. Lancet Infect Dis 2007;7(9):614-24.

9. Healy CM, Munoz FM, Rench MA, Halasa NB, et al. Prevalence of pertussis antibodies in maternal delivery, cord, and infant serum. I Infect Dis 2004;190(2):335-40.

10. Gonik B, Puder KS, Gonik N, Kruger M. Seroprevalence of Bordetella pertussis antibodies in mothers and their newborn infants. Infect Dis Obstet Gynecol 2005;13(2):59-61.

11. Nooitgedagt JE, de Greeff SC, Elvers BH, de Melker HE, et al. Seroprevalence of Bordetella pertussis infection during pregnancy measured by $\operatorname{IgG}$ antibodies against pertussis toxin. Clin Infect Dis 2009;49(7):1086-9.

12. Fallo A, Manonelles G, Hozbor D, Lara C, et al. Estudio de seroprevalencia de coqueluche en adultos jóvenes, mujeres en puerperioinmediato y sangre del cordón umbilical. Arch Argent Pediatr 2014;112(4):315-22.
13. Edwards KM. Pertussis: an important target for maternal immunization. Vaccine 2003;21(24):3483-6.

14. Haberling DL, Holman RC, Paddock CD, Murphy TV. Infant and maternal risk factors for pertussis-related infant mortality in the United States, 1999 to 2004. Pediatr Infect Dis J 2009;28(3):194-8.

15. Heininger U, Riffelmann M, Leineweber B, Wirsing von Koenig $\mathrm{CH}$. Maternally derived antibodies against Bordetella pertussis antigens pertussis toxin and filamentous hemagglutinin in preterm and full term newborns. Pediatr Infect Dis J 2009;28(5):443-5.

16. Schwartz KL, Kwong JC, Deeks SL, Campitelli MA, et al. Effectiveness of pertussis vaccination and duration of immunity. CMAJ 2016;188(16):E399-E406.

17. Huang CC, Chen PM, KuoJK, Chiu WH, et al. Experimental Whooping cough. N Engl J Med 1962;266:105-11.

18. Healy CM, Rench MA, Edwards KM, Baker CJ. Pertussis serostatus among neonates born to Hispanic women. Clin Infect Dis 2006;42(10):1439-42.

19. Plans P, Jansà J, Doshi N, Harrison TG, et al. Prevalence of pertussis antibodies in umbilical cord blood samples in Catalonia, Spain. Pediatr Infect Dis J 2008;27(11):1023-5.

20. Izurieta HS, Kenyon TA, Strebel PM, Baughman AL, et al. Risk factors for pertussis in young infants during an outbreak in Chicago in 1993. Clin Infect Dis 1996;22(3): 503-7.

21. Amirthalingam G, Andrews N, Campbell H, RibeiroS, et al. Effectiveness of maternal pertussis vaccination in England: an observational study. Lancet 2014;384(9953):1521-8.

22. Amirthalingam G, Campbell $H$, Ribeiro S, Fry NK, et al. Sustained effectiveness of the maternal pertussis immunization program in England 3 years following introduction. Clin Infect Dis 2016;63(suppl 4):S236-43.

23. Joint Committee on Vaccination and Immunisation. Minute of the meeting on 3 February 2016. [Acceso: 6 de enero de 2017]. Disponible en: https: / / app.box.com/s /iddfb4ppw kmtjusir2tc/1/2199012147/66698939189/1.

24. Eberhardt CS, Blanchard-Rohner G, Lemaître B, Boukrid M, et al. Maternal immunization earlier in pregnancy maximizes antibody transfer and expected infant seropositivity against pertussis. Clin Infect Dis 2016;62(7):829-36.
CONSENSO de ENFERMEDADES INFECCIOSAS REGIONALES de ARGENTINA Sociedad Argentina de Pediatria

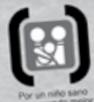

Este libro, elaborado por el Comité de Infectología, aborda muy claramente las patologías infecciosas regionales de la Argentina. Es el primero que la SAP edita sobre este tema con la convicción que será de suma utilidad para los pediatras.

\author{
Contenidos: Hidatidosis, Triquinosis, Fiebre Hemorrágica \\ Argentina, Bruselosis, Leptospirosis, Chagas, Paludismo, \\ Encefalitis de Saint Louis y West Nile, Fiebre Amarilla, \\ Dengue y Coccidiodomicosis.
}

Para toda información, ponerse en contacto con: elsa.contaduria@sap.org.ar 